\title{
A dataset on type specimens of hemipteran insects in China
}

\author{
Junjie $\mathrm{Li}^{\ddagger}$, Huanhuan Liü, Yangxue $\mathrm{Wu}^{\ddagger}$, Longqin $\mathrm{Ye}^{\ddagger}$, Xiaolei Huang ${ }^{\ddagger}$ \\ ‡ State Key Laboratory of Ecological Pest Control for Fujian and Taiwan Crops, College of Plant Protection, Fujian Agriculture \\ and Forestry University, Fuzhou, China
}

Corresponding author: Xiaolei Huang (huangxl@fafu.edu.cn)

Academic editor: Laurence Livermore

Received: 15 Feb 2021 | Accepted: 21 Jun 2021 | Published: 29 Jun 2021

Citation: Li J, Liu H, Wu Y, Ye L, Huang X (2021) A dataset on type specimens of hemipteran insects in China.

Biodiversity Data Journal 9: e64443. https://doi.org/10.3897/BDJ.9.e64443

\section{Abstract \\ Background}

Type specimens are valuable resources for investigating and exploring biodiversity on Earth, which has high academic and conservation value. Hemipteran insects are one of the most important and diverse groups in Insecta and their type specimens have important reference value for many research fields. So far, the data on the type specimens of the Hemiptera in China have not been fully collated.

\section{New information}

Through extensive literature review, we have constructed a dataset of type specimens for the new species of hemipteran insects in China published from 1950 to 2017, which includes the data such as collection date, specimen gender, preservation institution and geographical distribution. A total of 6,583 type specimen records were collected, covering 3,783 new species belonging to 1,299 genera and 88 families. This dataset can support the international community in conducting research on taxonomy, biodiversity, evolution and pest management. 


\section{Keywords}

type specimen, Hemiptera, biodiversity, distribution, China

\section{Introduction}

Type specimens include name bearing specimens that have been designated by researchers when describing and publishing new species, such as holotypes and syntypes, which can be used as standard references for subsequent taxonomic investigation (Robins on 1975, Mutanen et al. 2015). The number of type specimens reflects not only the research status of taxonomy, but also the historical resource accumulation of a country or region (Yang 2013). The type specimens, including holotype, allotype, paratype and syntypes, are the most authentic and direct manifestations and physical records of various organisms in nature (He et al. 2019). In addition to being the basis and carrier for the establishment of new taxonomic categories (Haber 2012), they are also important references for carrying out research in biodiversity science, ecology and evolutionary biology and protecting biological resources (Cui et al. 2009, Bebber et al. 2012, Peterson 2014).

Hemiptera (Arthropoda: Insecta) is not only the largest hemimetabolous order in the Insecta (Li et al. 2017), but also one of the most important and diverse insect groups (Schu $\mathrm{h}$ and Slater 1995). They are widely distributed around the world, with about 103,590 species having been recorded (Stork 2018). Most of them are phytophagous, therefore, they include important pests in agriculture and forestry, such as aphids, scale insects, leafhoppers as well as planthoppers (Forero 2008, Guo and Yuan 2016, Li et al. 2019). The type specimens of hemipteran insects are important references for the study of taxonomy, systematics, biogeography and pest control. China has a vast territory and spans two zoogeographic regions, the Palaearctic Region and the Oriental Region (Chen et al. 2008, Lei et al. 2015). Due to its heterogeneous environment and diverse habitat types, China is one of the most biologically diverse countries in the world (Myers et al. 2000, Tang et al. 2006, Lu et al. 2018). Up to now, however, the data of type specimens of Chinese hemipteran insects have not been well organised. There is no comprehensive digital resource of hemipteran type specimens available for scientists. In view of the importance of insect type specimens in entomology and biodiversity research, we have constructed a type specimen dataset of the Chinese hemipteran insects in order to provide basic references for future studies.

\section{General description}

Purpose: The aim of this work is to compile the dataset of type specimens of the Hemiptera in China.

Additional information: The collection date, specimen gender, preservation institution, geographical distribution and other related information of the holotypes, allotypes and 
paratypes for species of Hemiptera have been recorded in detail from various data sources, including scientific journals, serial publications, local chronicles, monographs and books. We have compiled almost all type specimen information for hemipteran insects published from 1950 to 2017 in China. The final dataset contains 6,583 records of 3,783 Hemiptera belonging to 1,299 genera and 88 families (Table 1) and covering a large number of areas (Fig. 1). A total of 418 authors participated in the description of the type specimens of Hemiptera and all type specimens are stored in 84 preservation institutions from 14 countries including China, the United Kingdom, Russia, the United States, Australia, Poland, France, Belgium, Japan, Austria, Germany, Netherlands, Singapore and India, among which all holotypes are stored in 66 preservation institutions in 10 countries. The holotype of most species (3,596 species, 99.39\%) are preserved in China, with only 22 species $(0.61 \%)$ stored in nine other countries, as shown in the Table 2.

\section{Table 1.}

The diversity of Hemipteran insects included in this dataset.

\begin{tabular}{|c|c|c|c|c|}
\hline Families & No. of species & Percentage of all species (\%) & No. of genera & Percentage of all genera (\%) \\
\hline Cicadellidae & 1120 & 29.61 & 256 & 19.71 \\
\hline Miridae & 244 & 6.45 & 73 & 5.62 \\
\hline Aphididae & 233 & 6.16 & 112 & 8.62 \\
\hline Psyllidae & 221 & 5.84 & 33 & 2.54 \\
\hline Membracidae & 179 & 4.73 & 41 & 3.16 \\
\hline Delphacidae & 169 & 4.47 & 88 & 6.77 \\
\hline Reduviidae & 154 & 4.07 & 66 & 5.08 \\
\hline Coreidae & 128 & 3.38 & 56 & 4.31 \\
\hline Diaspididae & 109 & 2.88 & 49 & 3.77 \\
\hline Pentatomidae & 109 & 2.88 & 53 & 4.08 \\
\hline Lygaeidae & 88 & 2.33 & 40 & 3.08 \\
\hline Triozidae & 86 & 2.27 & 20 & 1.54 \\
\hline Cicadidae & 75 & 1.98 & 34 & 2.62 \\
\hline Urostylidae & 56 & 1.48 & 5 & 0.38 \\
\hline Aradidae & 55 & 1.45 & 24 & 1.85 \\
\hline Pseudococcidae & 53 & 1.4 & 32 & 2.46 \\
\hline Pemphigidae & 46 & 1.22 & 20 & 1.54 \\
\hline Nabidae & 42 & 1.11 & 11 & 0.85 \\
\hline Anthocoridae & 37 & 0.98 & 6 & 0.46 \\
\hline
\end{tabular}




\begin{tabular}{|c|c|c|c|c|}
\hline Families & No. of species & Percentage of all species (\%) & No. of genera & Percentage of all genera (\%) \\
\hline Plataspidae & 36 & 0.95 & 9 & 0.69 \\
\hline Lachnidae & 35 & 0.93 & 8 & 0.62 \\
\hline Tingidae & 34 & 0.9 & 21 & 1.62 \\
\hline Acanthosomatidae & 29 & 0.77 & 7 & 0.54 \\
\hline Callaphididae & 28 & 0.74 & 15 & 1.15 \\
\hline Aphrophoridae & 22 & 0.58 & 5 & 0.38 \\
\hline Issidae & 21 & 0.56 & 10 & 0.77 \\
\hline Veliidae & 21 & 0.56 & 5 & 0.38 \\
\hline Drepanosiphidae & 18 & 0.48 & 11 & 0.85 \\
\hline Achilidae & 18 & 0.48 & 5 & 0.38 \\
\hline Aphalaridae & 17 & 0.45 & 11 & 0.85 \\
\hline Chaitophoridae & 17 & 0.45 & 3 & 0.23 \\
\hline Cercopidae & 15 & 0.4 & 10 & 0.77 \\
\hline Derbidae & 15 & 0.4 & 8 & 0.62 \\
\hline Cydnidae & 14 & 0.37 & 8 & 0.62 \\
\hline Ricaniidae & 14 & 0.37 & 7 & 0.54 \\
\hline Berytidae & 13 & 0.34 & 5 & 0.38 \\
\hline Margarodidae & 13 & 0.34 & 4 & 0.31 \\
\hline Hormaphididae & 12 & 0.32 & 10 & 0.77 \\
\hline Tropiduchidae & 12 & 0.32 & 7 & 0.54 \\
\hline Asterolecaniidae & 10 & 0.26 & 5 & 0.38 \\
\hline Greenideidae & 10 & 0.26 & 4 & 0.31 \\
\hline Flatidae & 9 & 0.24 & 7 & 0.54 \\
\hline Coccidae & 9 & 0.24 & 7 & 0.54 \\
\hline Kinnaridae & 7 & 0.19 & 2 & 0.15 \\
\hline Dictyopharidae & 7 & 0.19 & 5 & 0.38 \\
\hline Adelgidae & 6 & 0.16 & 4 & 0.31 \\
\hline Cixiidae & 6 & 0.16 & 5 & 0.38 \\
\hline Eurybrachidae & 6 & 0.16 & 1 & 0.08 \\
\hline Machaerotidae & 6 & 0.16 & 2 & 0.15 \\
\hline
\end{tabular}




\begin{tabular}{|c|c|c|c|c|}
\hline Families & No. of species & Percentage of all species (\%) & No. of genera & Percentage of all genera (\%) \\
\hline Piesmatidae & 6 & 0.16 & 1 & 0.08 \\
\hline Aleyrodidae & 5 & 0.13 & 5 & 0.38 \\
\hline Fulgoridae & 5 & 0.13 & 3 & 0.23 \\
\hline Pyrrhocoridae & 5 & 0.13 & 5 & 0.38 \\
\hline Kermesidae & 5 & 0.13 & 2 & 0.15 \\
\hline Aphelocheiridae & 4 & 0.11 & 1 & 0.08 \\
\hline Calophyidae & 4 & 0.11 & 2 & 0.15 \\
\hline Ceratocombidae & 4 & 0.11 & 1 & 0.08 \\
\hline Schizopteridae & 4 & 0.11 & 4 & 0.31 \\
\hline Kerriidae & 4 & 0.11 & 4 & 0.31 \\
\hline Velocipedidae & 4 & 0.11 & 1 & 0.08 \\
\hline Eriococcidae & 3 & 0.08 & 3 & 0.23 \\
\hline Gerridae & 3 & 0.08 & 2 & 0.15 \\
\hline Lecaniodiaspididae & 3 & 0.08 & 3 & 0.23 \\
\hline Meenoplidae & 3 & 0.08 & 2 & 0.15 \\
\hline Thelaxidae & 3 & 0.08 & 1 & 0.08 \\
\hline Rhyparochromidae & 3 & 0.08 & 1 & 0.08 \\
\hline Nogodinidae & 3 & 0.08 & 1 & 0.08 \\
\hline Lophopidae & 2 & 0.05 & 2 & 0.15 \\
\hline Caliscelidae & 2 & 0.05 & 1 & 0.08 \\
\hline Saldidae & 2 & 0.05 & 2 & 0.15 \\
\hline Stenocephalidae & 2 & 0.05 & 2 & 0.15 \\
\hline Scutelleridae & 2 & 0.05 & 2 & 0.15 \\
\hline Eubranchidae & 2 & 0.05 & 2 & 0.15 \\
\hline Rhophalidae & 2 & 0.05 & 2 & 0.15 \\
\hline Notonectidae & 1 & 0.03 & 1 & 0.08 \\
\hline Cerococcidae & 1 & 0.03 & 1 & 0.08 \\
\hline Naucoridae & 1 & 0.03 & 1 & 0.08 \\
\hline Anoeciidae & 1 & 0.03 & 1 & 0.08 \\
\hline Leptopodidae & 1 & 0.03 & 1 & 0.08 \\
\hline
\end{tabular}




\begin{tabular}{|c|c|c|c|c|}
\hline Families & No. of species & Percentage of all species (\%) & No. of genera & Percentage of all genera (\%) \\
\hline Isometopidae & 1 & 0.03 & 1 & 0.08 \\
\hline Liviidae & 1 & 0.03 & 1 & 0.08 \\
\hline Lyctocoridae & 1 & 0.03 & 1 & 0.08 \\
\hline Mindaridae & 1 & 0.03 & 1 & 0.08 \\
\hline Kuwaniidae & 1 & 0.03 & 1 & 0.08 \\
\hline Aclerdidae & 1 & 0.03 & 1 & 0.08 \\
\hline Tessaratomidae & 1 & 0.03 & 1 & 0.08 \\
\hline Phloeomyzidae & 1 & 0.03 & 1 & 0.08 \\
\hline Colobathristidae & 1 & 0.03 & 1 & 0.08 \\
\hline Total & 3783 & 100 & 1299 & 100 \\
\hline
\end{tabular}

Table 2.

The number of holotypes of Hemipteran species preserved by different preservation institutions.

\begin{tabular}{|c|c|c|c|}
\hline Preservation institution of Holotype & Country & No. of species & Percentage (\%) \\
\hline IZAS & China & 911 & 25.18 \\
\hline NWAFU & China & 590 & 16.31 \\
\hline NKU & China & 534 & 14.76 \\
\hline CAU & China & 409 & 11.3 \\
\hline GU & China & 387 & 10.7 \\
\hline AAU & China & 210 & 5.8 \\
\hline TNHM & China & 120 & 3.32 \\
\hline NJAU & China & 101 & 2.79 \\
\hline IPPE & China & 71 & 1.96 \\
\hline IMNU & China & 53 & 1.46 \\
\hline SAU & China & 38 & 1.05 \\
\hline SYSU & China & 37 & 1.02 \\
\hline KZAS & China & 13 & 0.36 \\
\hline BFUC & China & 13 & 0.36 \\
\hline NWIPB & China & 12 & 0.33 \\
\hline ZJAFU & China & 10 & 0.28 \\
\hline SDAU & China & 8 & 0.22 \\
\hline
\end{tabular}




\begin{tabular}{|c|c|c|c|}
\hline Preservation institution of Holotype & Country & No. of species & Percentage (\%) \\
\hline JXAU & China & 8 & 0.22 \\
\hline BMNH & UK & 7 & 0.19 \\
\hline IAPQ & China & 6 & 0.17 \\
\hline NMNS & China & 5 & 0.14 \\
\hline ZIN & Russia & 4 & 0.11 \\
\hline MSTC & China & 4 & 0.11 \\
\hline ICSCU & China & 4 & 0.11 \\
\hline SAAS & China & 4 & 0.11 \\
\hline BJMNH & China & 4 & 0.11 \\
\hline FAFU & China & 3 & 0.08 \\
\hline SNU & China & 3 & 0.08 \\
\hline AHUT & China & 3 & 0.08 \\
\hline INRSC & China & 3 & 0.08 \\
\hline ISCK & China & 3 & 0.08 \\
\hline SWU & China & 2 & 0.06 \\
\hline RIRI & China & 2 & 0.06 \\
\hline HBAU & China & 2 & 0.06 \\
\hline ZISP & Russia & 2 & 0.06 \\
\hline ANIC & Australia & 2 & 0.06 \\
\hline SU & China & 1 & 0.03 \\
\hline SCAU & China & 1 & 0.03 \\
\hline AHFP & China & 1 & 0.03 \\
\hline HBAF & China & 1 & 0.03 \\
\hline FDYN & China & 1 & 0.03 \\
\hline FJAS & China & 1 & 0.03 \\
\hline GZAS & China & 1 & 0.03 \\
\hline NMCU & UK & 1 & 0.03 \\
\hline HSFB & China & 1 & 0.03 \\
\hline HBMN & China & 1 & 0.03 \\
\hline HEBNU & China & 1 & 0.03 \\
\hline
\end{tabular}




\begin{tabular}{|c|c|c|c|}
\hline Preservation institution of Holotype & Country & No. of species & Percentage (\%) \\
\hline GZAF & China & 1 & 0.03 \\
\hline MNHN & France & 1 & 0.03 \\
\hline NEFU & China & 1 & 0.03 \\
\hline SCU & China & 1 & 0.03 \\
\hline YZU & China & 1 & 0.03 \\
\hline PCPC & China & 1 & 0.03 \\
\hline NHMW & Austria & 1 & 0.03 \\
\hline $\mathrm{NCHU}$ & China & 1 & 0.03 \\
\hline TARI & China & 1 & 0.03 \\
\hline CATAS & China & 1 & 0.03 \\
\hline YLNU & China & 1 & 0.03 \\
\hline PPLS & China & 1 & 0.03 \\
\hline IMAU & China & 1 & 0.03 \\
\hline PSQS & China & 1 & 0.03 \\
\hline NCSU & USA & 1 & 0.03 \\
\hline MIZ & Poland & 1 & 0.03 \\
\hline IAEAS & China & 1 & 0.03 \\
\hline IRSNB & Belgium & 1 & 0.03 \\
\hline HUS & Japan & 1 & 0.03 \\
\hline Total & & 3618 & 100 \\
\hline
\end{tabular}

This article provides a detailed description of the data source, structure and processing of the type specimen dataset of the Chinese hemipteran insects and presents the potential reuse value of this dataset. We are committed to making this dataset a dynamic one by following the principles of open science and constantly updating available new records. Through this work, we hope to promote further development of insect data collation and provide assistance to the research of biodiversity and entomology.

\section{Sampling methods}

\section{Sampling description: Data Sources}

The dataset mainly collected the type specimens of Chinese Hemiptera published by domestic and foreign scientists from 1950 to 2017. Our data sources consisted of two parts, one of which is mainly from the book series Catalogue of Insect Type Specimens 
Deposited in China (Cui et al. 2007, Cui et al. 2009, Bai et al. 2014). This series of books mainly records the data of insect type specimens produced in China published from 1950 to 2010 and the references mostly come from journals, chorographies, serial publications and monographs. Specifically, professional journals and chorographies mainly include the Acta Entomologica Sinica, Entomotaxonomia, Zoological Systematics, Wuyi Science Journal, Zoological Research, Acta Zoologica Sinica, Scientia Silvae Sinicae, Journal of Beijing Forestry University, Entomological Journal of East China, Journal of South China Agricultural University, Sichuan Journal of Zoology, Journal of Ningxia Agricultural College, Journal of Northwest Forestry University, Acta Agriculturae Boreali-occidentalis Sinica, Journal of Northwest A \& F University, Journal of Southwest Forestry College and the Journal of Southwest Agricultural University. Serial publications mainly include the Fauna Sinica, Collected Papers of Entomological Research, the Insect Fauna in Henan Province and the Insects of Fujian Province. Monographs mainly include the Insects of the Hengduan Mountains and the Insects of the Three Gorge Reservoir Area of Yangtze River.

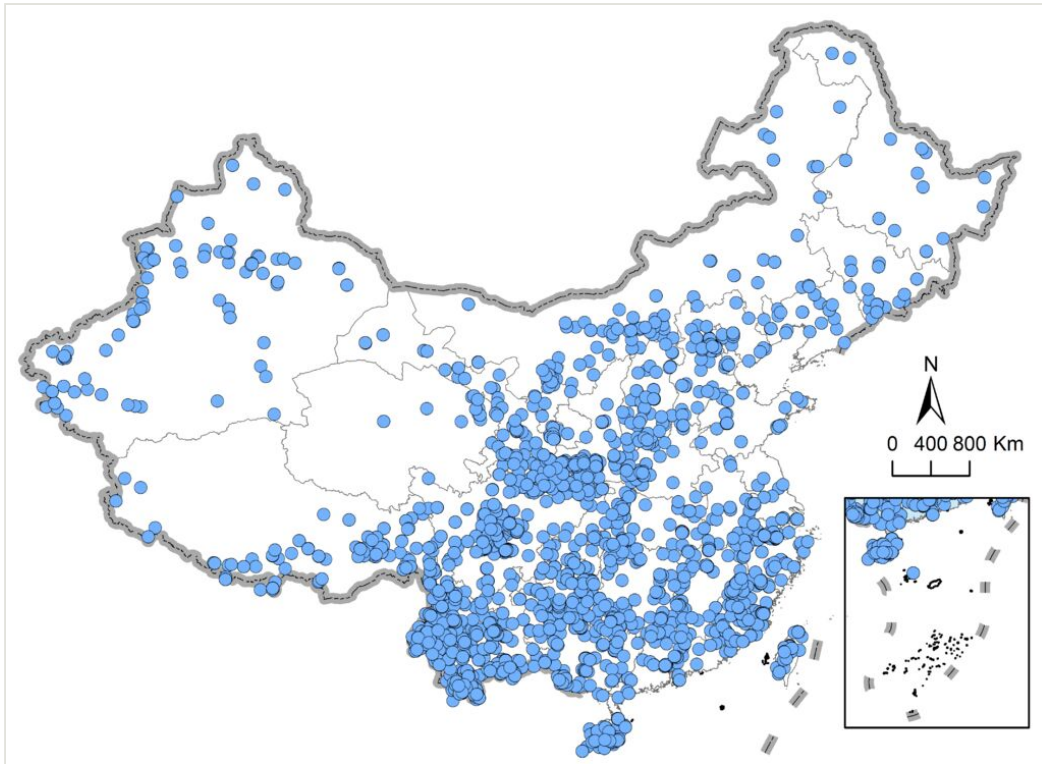

Figure 1. doi

Geographical locations of the type specimens of Chinese hemipteran insects.

In addition, we also searched relevant literature published from 2000 to 2017 based on the Zoological Records in order to include recent species records and make the dataset more comprehensive. The search entry used was (new speci* or new tax ${ }^{*}$ ) and (Hemiptera or Homoptera) and (China). We retrieved 371 literature records, with information including the authors, title, abstract, publication date and journal information of each record. Based on these records, we obtained complete published article for subsequent specimen data collection. There were eight records about extinct species and one without a new species description, which was excluded from data collection. 


\section{Data collection and processing}

We searched and collected the type specimen information of each new Hemiptera, including the species/subspecies name and its taxonomic status, the year of publication, as well as the gender, distribution, preservation institution and collection date of the holotype, allotype and paratype, respectively. In addition, each row of data was marked with its literature source and literature authors. In the original literature, several items, such as the species name, literature authors, preservation institution and collection date, were expressed in various ways. For example, some species names were with named person, while others were not. The literature authors might include both Chinese and foreign colleagues, and their names were written in different formats. Some names of preservation institutions were abbreviated, while others were with full names. Therefore, for the species names, we standardised them into the form of genus name plus species name. Literature authors were standardised as the last names followed by the initials of given names. The collection date was recorded as year, month and day. We used abbreviations for all preservation institutions for the sake of standardisation and their corresponding full names were shown in Table 3. Most literature only recorded the names of collection localities of the type specimens. In order to make the dataset more convenient for future users, we georeferenced the longitude and latitude of each distribution site using Google Maps. The coordinate precision is approximately $1,000 \mathrm{~m}$. We recorded the few distribution records that provided coordinates. We translated the names of distribution sites from Chinese into English. For the literature sources, due to many species being published in Chinese, we compiled a separate 'Literature' column uniformly presented in English, but retained the original Chinese literature information in a 'Original literature' column.

Table 3.

Abbreviations and full names of the preservation institutions of type specimens for Hemipteran insects in China.

\begin{tabular}{|l|l|l|}
\hline Abbreviation & Country & The full name of the preservation institution \\
\hline AAU & China & Anhui Agricultural University, Hefei, Anhui, China \\
\hline AFNX & China & Ningxia Academy of Agriculture and Forestry Sciences, Ningxia, China \\
\hline AHFP & China & Anhui Forest Pest Control Station, Hefei, Anhui, China \\
\hline AHUT & China & Anhui University of Technology, Maanshan, Anhui, China \\
\hline ANIC & Australia & Australian National Insect Collection, CSIRO, Canberra, Australia \\
\hline BFUC & China & $\begin{array}{l}\text { Insect Collection, the Department of Forestry Protection, Beijing Forestry University, } \\
\text { Beijing, China }\end{array}$ \\
\hline BJMNH & China & Beijing Museum of Nature History, Beijing, China \\
\hline BMHU & USA & Bhopal Museum, Hawaii, USA \\
\hline BMNH & UK & Natural History Museum, London, UK \\
\hline BPBM & USA & Bernice P. Bishop Museum, Honolulu, Hawaii, USA \\
\hline
\end{tabular}




\begin{tabular}{|c|c|c|}
\hline CATAS & China & $\begin{array}{l}\text { Chinese Academy of Tropical Agricultural Sciences Environment and Plant Protection } \\
\text { Institute, Haikou, Hainan, China }\end{array}$ \\
\hline CAU & China & Department of Entomology, China Agricultural University, Beijing, China \\
\hline CDFA & USA & California Department of Food and Agriculture, Sacramento, CA, USA \\
\hline CEHI & Austria & Collection Ernst Heiss, Tiroler Landesmuseum, Innsbruck, Austria \\
\hline CLHC & China & Collection of $\mathrm{Li} \mathrm{He}$, Chengdu, China \\
\hline FAFU & China & $\begin{array}{l}\text { College of Plant Protection, Fujian Agriculture Forestry University, Fuzhou, Fujian, } \\
\text { China }\end{array}$ \\
\hline FAHN & China & Hunan Academy of Forestry, Changsha, Hunan, China \\
\hline FDYN & China & The Forestry Department of Yunnan Province, Kunming, Yunnan, China \\
\hline FJAS & China & Institute of Entomology, Fujian Agriculture of Science, Fuzhou, Fujian, China \\
\hline GU & China & Guizhou University, Guiyang, Guizhou, China \\
\hline GXAS & China & $\begin{array}{l}\text { Biological Research Laboratory, Guangxi Academy of Sciences, Nanning, Guangxi, } \\
\text { China }\end{array}$ \\
\hline GZAF & China & Guizhou Academy of Forestry, Guiyang, Guizhou, China \\
\hline GZAS & China & Guizhou Academy of Sciences, Guiyang, Guizhou, China \\
\hline HBAF & China & $\begin{array}{l}\text { Shijiazhuang Orchard Research Institute, Hebei Academy of Agriculture and Forestry } \\
\text { Sciences, Shijiazhuang, Hebei, China }\end{array}$ \\
\hline HBAU & China & Agricultural University of Huabei, Baoding, Hebei, China \\
\hline HBMN & China & Museum of Natural History, Harbin, Heilongjiang, China \\
\hline HBU & China & Hebei University, Baoding, China \\
\hline HEBNU & China & Hebei Normal University, Shijiazhuang, Hebei, China \\
\hline HSFB & China & Huangshan City Forestry Bureau of Anhui Province, Huangshan, Anhui, China \\
\hline HUS & Japan & Laboratory of Systematic Entomology, Hokkaido University, Sapporo, Japan \\
\hline IAEAS & China & $\begin{array}{l}\text { Shenyang Institute of Applied Ecology, Chinese Academy of Sciences, Shenyang, } \\
\text { Liaoning, China }\end{array}$ \\
\hline IAPQ & China & Institute of Animal and Plant Quarantine, Yunnan, China \\
\hline ICSCU & China & $\begin{array}{l}\text { Insect Collection, Gold Mantis School of Architecture and Urban Environment, } \\
\text { Soochow University, Suzhou, Jiangsu, China }\end{array}$ \\
\hline IMAU & China & Inner Mongolia College of Forestry, Hohhot, Inner Mongolia, China \\
\hline IMNU & China & Inner Mongolia Normal University, Hohhot, Inner Mongolia, China \\
\hline INRSC & China & Institute for Natural Resources in Sichuan, Chengdu, Sichuan, China \\
\hline IPPE & China & $\begin{array}{l}\text { Shanghai Institute of Biological Sciences, Chinese Academy of Sciences, Shanghai, } \\
\text { China }\end{array}$ \\
\hline IRSNB & Belgium & The Institut royal des Sciences naturelles de Belgique, Bruxelles, Belgium \\
\hline IRTUA & Japan & $\begin{array}{l}\text { Laboratory of Insect Resources, Faculty of Agriculture, Tokyo University of Agriculture, } \\
\text { Atsugi, Japan }\end{array}$ \\
\hline
\end{tabular}




\begin{tabular}{|c|c|c|}
\hline ISCK & China & $\begin{array}{l}\text { The Institute of South China Karst, Guizhou Normal University, Guiyang, Guizhou, } \\
\text { China }\end{array}$ \\
\hline IZAS & China & Institute of Zoology, Chinese Academy of Sciences, Beijing, China \\
\hline JXAU & China & Jiangxi Agricultural University, Nanchang, Jiangxi, China \\
\hline KZAS & China & $\begin{array}{l}\text { Kunming Institute of Zoology, Chinese Academy of Sciences, Kunming, Yunnan, } \\
\text { China }\end{array}$ \\
\hline MIZ & Poland & Museum and Institute of Zoology PAS, Warsaw, Poland \\
\hline MNHN & France & The Muséum national d'Histoire naturelle, Paris, France \\
\hline MNHU & Germany & Museum fuĖr Naturkunde der Humboldt-UniversitaĖt, Berlin, Germany \\
\hline MSTC & China & Anhui Maanshan Science and Technology Commission, Maanshan, Anhui, China \\
\hline $\mathrm{NCHU}$ & China & National Chung Hsing University, Taichung, Taiwan, China \\
\hline NCSU & USA & North Carolina State University Insect Collection, Raleigh, North Carolina, USA \\
\hline NCTN & Netherlands & Nieser and Chen Collection, Tiel, The Netherlands \\
\hline NEFU & China & $\begin{array}{l}\text { Institute of Entomology, College of Forestry, Northeast Forestry University, Harbin, } \\
\text { Heilongjiang, China }\end{array}$ \\
\hline NHMW & Austria & Naturehistorisches Museum in Wien, Wien, Austria \\
\hline NJAU & China & Nanjing Agricultural University, Nanjing, Jiangsu, China \\
\hline NKU & China & Institute of Entomology, College of Life Sciences, Nankai University, Tianjin, China \\
\hline NMCU & UK & National Museum of Cardiff, UK \\
\hline NMNS & China & National Museum of Natural Science, Taichung, Taiwan, China \\
\hline NWAFU & China & Entomological Museum of Northwest A\&F University, Yangling, Shaanxi, China \\
\hline NWIPB & China & $\begin{array}{l}\text { Northwest Institute of Plateau Biology, Chinese Academy of Sciences, Xining, } \\
\text { Qinghai, China }\end{array}$ \\
\hline PCPC & China & Private Collection of Pingping Chen, Beijing, China \\
\hline PPLS & China & $\begin{array}{l}\text { Plant Protection Laboratory of Shenyang Garden Science Institute, Shenyang, } \\
\text { Liaoning, China }\end{array}$ \\
\hline PSQS & China & The Plant Protection Station of Qiannan State, Guizhou, China \\
\hline RIRI & China & $\begin{array}{l}\text { Research Institute of Resource Insects, Chinese Academy of Forestry, Kunming, } \\
\text { Yunnan, China }\end{array}$ \\
\hline RMNUS & Singapore & $\begin{array}{l}\text { Zoological Reference Collection, Raffles Museum of Biodiversity Research, National } \\
\text { University of Singapore, Singapore }\end{array}$ \\
\hline SAAS & China & $\begin{array}{l}\text { College of Plant protection, Sichuan Academy of Agricultural Sciences, Chengdu, } \\
\text { Sichuan, China }\end{array}$ \\
\hline SAU & China & Insect Collection of Shanxi Agricultural University, Taigu, Shanxi, China \\
\hline SCAU & China & South China Agricultural University, Guangzhou, Guangdong, China \\
\hline SCU & China & $\begin{array}{l}\text { Animal Herbarium, College of Life Sciences, Sichuan University, Chengdu, Sichuan, } \\
\text { China }\end{array}$ \\
\hline
\end{tabular}




\begin{tabular}{|c|c|c|}
\hline SDAU & China & $\begin{array}{l}\text { The Research Center of Scale Insects, Shandong Agricultural University, Tai'an, } \\
\text { Shandong, China }\end{array}$ \\
\hline SHBG & China & Shanghai Botanical Garden, Shanghai, China \\
\hline SNU & China & Shaanxi Normal University, Xi'an, Shanxi , China \\
\hline SU & China & $\begin{array}{l}\text { Department of horticultural science and technology of Soochow University, Suzhou, } \\
\text { Jiangsu, China }\end{array}$ \\
\hline SWU & China & Southwest University, Chongqing, China \\
\hline SYSU & China & Sun Yat-sen University, Guangzhou, Guangdong, China \\
\hline TARI & China & Taiwan Agricultural Research Institute, Taichung, Taiwan, China \\
\hline TNHM & China & Tianjin Natural History Museum, Tianjin, China \\
\hline USNM & USA & National Museum of Natural History, Washington D.C., USA \\
\hline XIEG & China & Xinjiang Institute of Ecology and Geography, Chinese Academy of Sciences, China \\
\hline YIB & Russia & Institute for Biological Problems of Cryolithozone RAS, Yakutsk, Russia \\
\hline YLNU & China & College of Life Sciences, Yulin Normal University, Yulin, Guangxi ,China \\
\hline YZU & China & Insect Collection of Yangzhou University, Yangzhou, Jiangsu, China \\
\hline ZIN & Russia & Russian Academy of Sciences, Zoological Institute, St.Petersburg, Russia \\
\hline ZISP & Russia & The Zoological Institute RAS, St. Petersburg, Russia \\
\hline ZJAFU & China & $\begin{array}{l}\text { The Research Center of Scale Insects, Zhejiang A\&F University, Lin'an, Zhejiang, } \\
\text { China }\end{array}$ \\
\hline ZSI & India & Zoological Survey of India \\
\hline
\end{tabular}

Quality control: After the completion of the original data collection, we checked all data records individually and standardised the format. In order to investigate whether the taxonomic information of each species/subspecies has changed, we checked the species/ subspecies name and taxonomic status of each species/subspecies through the Catalogue of Life (http://www.catalogueoflife.org) and some other taxonomic websites for specific groups of Hemiptera, such as the Aphid Species File (http://aphid.speciesfile.org), the Systematic Database of the Scale Insects of the World (http://scalenet.info/catalogue), the Coreoidea Species File (http://Coreoidea.SpeciesFile.org) and the Lygaeoidea Species File (http://Lygaeoidea.speciesfile.org). If the species/subspecies name and its taxonomic status changed, we recorded them in corresponding fields of the dataset and the results showed that $11.9 \%$ of the species/subspecies names have changed since their original description. These changes are important records representing the taxonomic status of these species in different historical periods. In addition, we also checked and validated the geographical locations of the type specimens and their corresponding latitudes and longitudes in detail, based on original literature.

\section{Geographic coverage}

Description: China 
Coordinates: $3^{\circ} 51^{\prime} \mathrm{N}-53^{\circ} 33^{\prime} \mathrm{N} ; 73^{\circ} 33^{\prime} \mathrm{E}-135^{\circ} 05^{\prime} \mathrm{E}$.

\section{Taxonomic coverage}

Description: Type specimens information for a total of 3,783 species of Hemiptera belonging to 1,299 genera and 88 families was collected.

\section{Temporal coverage}

Notes: Time range: $1950-2017$

\section{Usage licence}

Usage licence: Creative Commons Public Domain Waiver (CC-Zero)

\section{Data resources}

Data package title: A dataset on type specimens of Hemipteran insects in China.

\section{Number of data sets: 1}

Data set name: A dataset on type specimens of Hemipteran insects in China.

Description: The final dataset is presented in Suppl. material 1, with the title of $A$ dataset on type specimens of Hemipteran insects in China. At the same time, the dataset is also deposited in the DataOpen repository: http://doi.org/10.24899/do. 202106001. The corresponding website is http://www.dataopen.info/home/datafile/ index/id/210. Each row of the dataset represents the type specimen information of a species/subspecies, and if a species/subspecies contains multiple paratypes, it corresponds to multiple rows. The dataset contains 30 fields, as shown below:

\begin{tabular}{|l|l|}
\hline Column label & Column description \\
\hline ID & The unique number for each record. \\
\hline Family & Family name of species/subspecies. \\
\hline Family change & $\begin{array}{l}\text { If the taxonomic status of a species/subspecies has changed in history, this } \\
\text { indicates its current family name. }\end{array}$ \\
\hline Genus & Genus name of species/subspecies. \\
\hline Genus change & If the taxonomic status of a species/subspecies has changed in history, this \\
\hline indicates its current genus name.
\end{tabular}




\begin{tabular}{|c|c|}
\hline $\begin{array}{l}\text { Species/Subspecies name } \\
\text { change }\end{array}$ & $\begin{array}{l}\text { If the name of a species/subspecies has changed in history, this indicates its } \\
\text { current name. }\end{array}$ \\
\hline $\begin{array}{l}\text { Species/Subspecies names in } \\
\text { the original literature }\end{array}$ & Species/Subspecies names recorded with various formats in original literature. \\
\hline Published year & The year in which the species/subspecies was published. \\
\hline Gender of holotype & $\begin{array}{l}\text { The gender of the holotype used for species/subspecies description. This data } \\
\text { item follows the original literature. }\end{array}$ \\
\hline Distribution of holotype & The geographical location of the holotype. \\
\hline Latitude of holotype & The latitude of the geographical location of the holotype. \\
\hline Longitude of holotype & The Longitude of the geographical location of the holotype. \\
\hline Collection time of holotype & Collection time of the holotype in a uniform format. \\
\hline $\begin{array}{l}\text { Preservation institution of } \\
\text { holotype }\end{array}$ & The abbreviation for the preservation institution of the holotype. \\
\hline Gender of allotype & $\begin{array}{l}\text { The gender of the allotype used for species/subspecies description. This data } \\
\text { item follows the original literature. }\end{array}$ \\
\hline Distribution of allotype & The geographical location of the allotype. \\
\hline Latitude of allotype & The latitude of the geographical location of the allotype. \\
\hline Longitude of allotype & The longitude of the geographical location of the allotype. \\
\hline Collection time of allotype & Collection time of the allotype in a uniform format. \\
\hline $\begin{array}{l}\text { Preservation institution of } \\
\text { allotype }\end{array}$ & The abbreviation for the preservation institution of the allotype. \\
\hline Gender of paratype & $\begin{array}{l}\text { The gender of the paratype used for species/subspecies description. This data } \\
\text { item follow the original literature. }\end{array}$ \\
\hline Distribution of paratype & The geographical location of the paratype. \\
\hline Latitude of paratype & The latitude of the geographical location of the paratype. \\
\hline Longitude of paratype & The longitude of the geographical location of the paratype. \\
\hline Collection time of paratype & Collection time of the paratype in a uniform format. \\
\hline $\begin{array}{l}\text { Preservation institution of } \\
\text { paratype }\end{array}$ & The abbreviation for the preservation institution of the paratype. \\
\hline Literature & $\begin{array}{l}\text { The literature source of the species/subspecies, which is uniformly presented in } \\
\text { English. If a journal name has been changed, its new name is reserved. }\end{array}$ \\
\hline Original literature & Original literature information without modification. \\
\hline Literature authors & The authors of the Literature. \\
\hline
\end{tabular}




\section{Acknowledgements}

This study was supported by National Key R\&D Program of China (2016YFE0203100) and Fujian Provincial Department of Science \& Technology (2015J06005).

\section{Author contributions}

X.H. and J.L. conceived and designed the study. J.L., H.L., Y.W. and L.Y. performed the data collection and collation. J.L. and X.H. executed the data analysis and drafted the manuscript. X.H. contributed resources during the study.

\section{References}

- $\quad$ Bai M, Cui JZ, Hu JY, Li LZ (2014) Catalogue of the insect type specimens deposited in China. Vol. III. China Forestry Publishing House, Beijing. [ISBN 978-7-5038-7736-0]

- Bebber D, Carine M, Davidse G, Harris D, Haston E, Penn M, Cafferty S, Wood JI, Scotland R (2012) Big hitting collectors make massive and disproportionate contribution to the discovery of plant species. Proceedings of the Royal Society B: Biological Sciences 279 (1736): 2269-2274. https://doi.org/10.1098/rspb.2011.2439

- $\quad$ Chen L, Song Y, Xu S (2008) The boundary of palaearctic and oriental realms in western China. Progress in Natural Science 18 (7): 833-841. https://doi.org/10.1016/ j.pnsc.2008.02.004

- $\quad$ Cui JZ, Bai M, Wu H, Ji LQ (2007) Catalogue of the insect type specimens deposited in China. Vol. I. China Forestry Publishing House, Beijing. [ISBN 978-7-5038-4904-6]

- Cui JZ, Bai M, Fan RJ, Wu H (2009) Catalogue of the insect type specimens deposited in China. Vol. II. China Forestry Publishing House, Beijing. [ISBN 978-5-5038-5448-4]

- Forero D (2008) The systematics of the Hemiptera. Revista Colombiana de Entomologia 34 (1): 1-21.

- Guo ZL, Yuan ML (2016) Research progress of mitochondrial genomes of Hemiptera insects. Scientia Sinica Vitae 46 (2): 151-166. https://doi.org/10.1360/n052015-00229

- Haber M (2012) How to misidentify a type specimen. Biology \& Philosophy 27 (6): 767-784. https://doi.org/10.1007/s10539-012-9336-0

- He P, Chen J, Qiao GX (2019) Current situation and future of biological collections of Chinese Academy of Sciences. Bulletin of the Chinese Academy of Sciences 34 (12): 1359-1370.

- $\quad$ Lei FM, Qu YH, Song G, Alström P, Fjeldså J (2015) The potential drivers in forming avian biodiversity hotspots in the East Himalaya Mountains of Southwest China. Integrative Zoology 10 (2): 171-181. https://doi.org/10.1111/1749-4877.12121

- $\quad$ Li H, Leavengood J, Chapman E, Burkhardt D, Song F, Jiang P, Liu JP, Zhou XG, Cai WZ (2017) Mitochondrial phylogenomics of Hemiptera reveals adaptive innovations driving the diversification of true bugs. Proceedings of the Royal Society B: Biological Sciences 284 (1862): 1-10. https://doi.org/10.1098/rspb.2017.1223

- $\quad$ Li JJ, Liu HH, Wu YX, Zeng LD, Huang XL (2019) Spatial patterns and determinants of the diversity of hemipteran insects in the Qinghai-Tibetan Plateau. Frontiers in Ecology and Evolution 7: 1-10. https://doi.org/10.3389/fevo.2019.00165 
- $\quad$ Lu LM, Mao LF, Yang T, Ye JF, Liu B, Li HL, Sun M, Miller J, Mathews S, Hu HH, Niu YT, Peng DX, Chen YH, Smith S, Chen M, Xiang KL, Le CT, Dang VC, Lu AM, Soltis P, Soltis D, Li JH, Chen ZD (2018) Evolutionary history of the angiosperm flora of China. Nature 554 (7691): 234-238. https://doi.org/10.1038/nature25485

- Mutanen M, Kekkonen M, Prosser SJ, Hebert PN, Kaila L (2015) One species in eight: DNAbarcodes from type specimens resolve a taxonomic quagmire. Molecular Ecology Resources 15 (4): 967-984. https://doi.org/10.1111/1755-0998.12361

- Myers N, Mittermeier R, Mittermeier C, da Fonseca GB, Kent J (2000) Biodiversity hotspots for conservation priorities. Nature 403 (6772): 853-858. https://doi.org/ $10.1038 / 35002501$

- $\quad$ Peterson AT (2014) Type specimens in modern ornithology are necessary and irreplaceable. The Auk 131 (3): 282-286. https://doi.org/10.1642/auk-13-204.1

- Robinson WH (1975) Type specimens vs. voucher specimens. Systematic Zoology 24 (1): 110-111. https://doi.org/10.2307/2412704

- $\quad$ Schuh R, Slater J (1995) True bugs of the world (Hemiptera: Heteroptera): classification and natural history. Cornell University Press [ISBN 978-0801420665]

- $\quad$ Stork N (2018) How many species of insects and other terrestrial arthropods are there on Earth? Annual Review of Entomology 63 (1): 31-45. https://doi.org/10.1146/annurevento-020117-043348

- $\quad$ Tang ZY, Wang ZH, Zheng CY, Fang JY (2006) Biodiversity in China's mountains. Frontiers in Ecology and the Environment 4 (7): 347-352. https://doi.org/10.1890/ 1540-9295(2006)004[0347:bicm]2.0.co;2

- Yang Y (2013) Holdings of type specimens of plants in herbaria of China. Biodiversity Science 20 (4): 512-516. https://doi.org/10.3724/sp.j.1003.2012.05076

\section{Supplementary material}

\section{Suppl. material 1: A dataset on type specimens of Hemipteran insects in China doi}

Authors: Junjie Li, Huanhuan Liu, Yangxue Wu, Longqin Ye, Xiaolei Huang Data type: A plain text table on the type specimens of Hemipteran insects in China Download file $(2.16 \mathrm{MB})$ 